\title{
Serum uric acid in smokers
}

\author{
Bassam E Hanna, Luma M Tohala, Jamal M Hamed
}

Department of Biochemistry, Nineveh College of Medicine, University of Mosul, Iraq

$\frac{\text { Received: } \quad \text { Accepted }}{\text { r.r.r.q. }}$

\section{ABSTRACT}

Objectives: To demonstrate the possible effect of smoking on serum uric acid level.

Methods: The study was conducted during the period from March to June $\uparrow \ldots \wedge$ in Mosul city as a case control study.

Participants: Subjects enrolled in this study were divided into two groups; nonsmokers and smokers composed of $\leqslant \vee$ and $\varepsilon$. apparently healthy male volunteers respectively with the same dietary habit, no pastmedical history of diabetes mellitus, hyperuricemia and gout , renal, lung or heart diseases or drug history affecting uric acid level. Smoker group is subdivided into heavy, moderate and mild smokers.

Fasting blood and random urine samples were obtained from both groups for measurement of uric acid and creatinine. Calculation of both urine uric acid/urine creatinine ratio and fraction excretion of uric acid were done.

Results: No significant differences in the age , serum creatinine, spot urine uric acid/urine creatinine ratio and fraction excretion of uric acid between two groups where as serum uric acid was significantly lower in smokers.

In smokers there are significant negative correlations of the average number of cigarette smoked/day and the duration of smoking with serum uric acid level.

Heavy, moderate and mild smokers showed no significant differences in the age , urine uric acid/urine creatinine ratio, fraction excretion of uric acid, serum creatinine and serum uric acid except a significant lower serum uric acid value in the heavy smoker compared with moderate and mild smokers .

Conclusion: The significant low serum uric acid level in smokers is due to the reduction of endogenous production as a result of chronic exposure to cigarette smoke that is a significant source of oxidative stress and as this reduction is proportionate with the duration and number of cigarette smoked/day and as low uric acid predispose to cardiovascular diseases as proved by other studies, therefore, its recommended for smokers to stop or reduce smoking with the use of serum uric acid as a routine test for follow-up as it is inexpensive, simple to reflect antioxidant level.

Keywords: Smokers, uric acid, cardiovascular disease

ألخلاصة

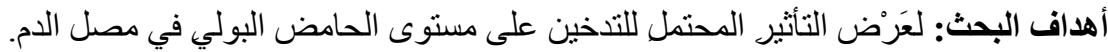

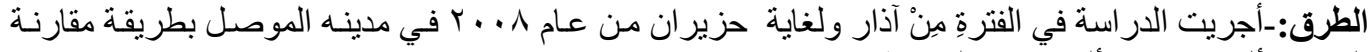

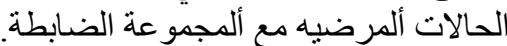

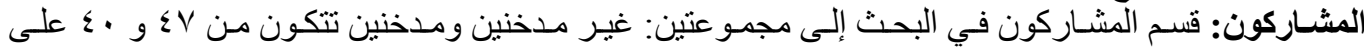

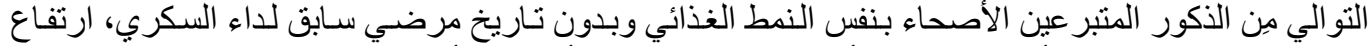

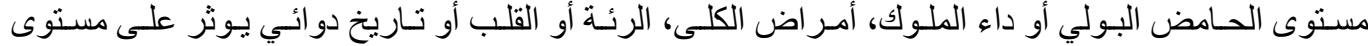

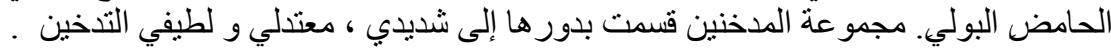

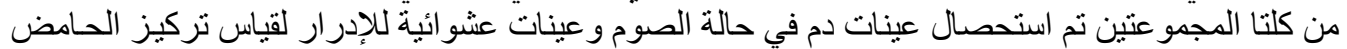

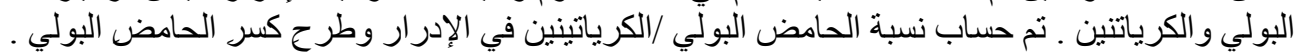

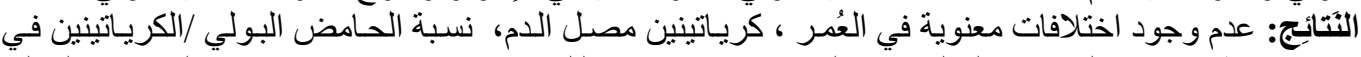

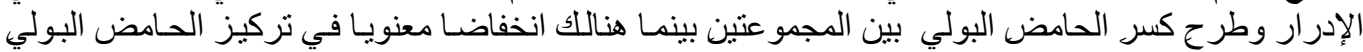

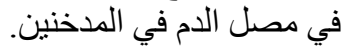




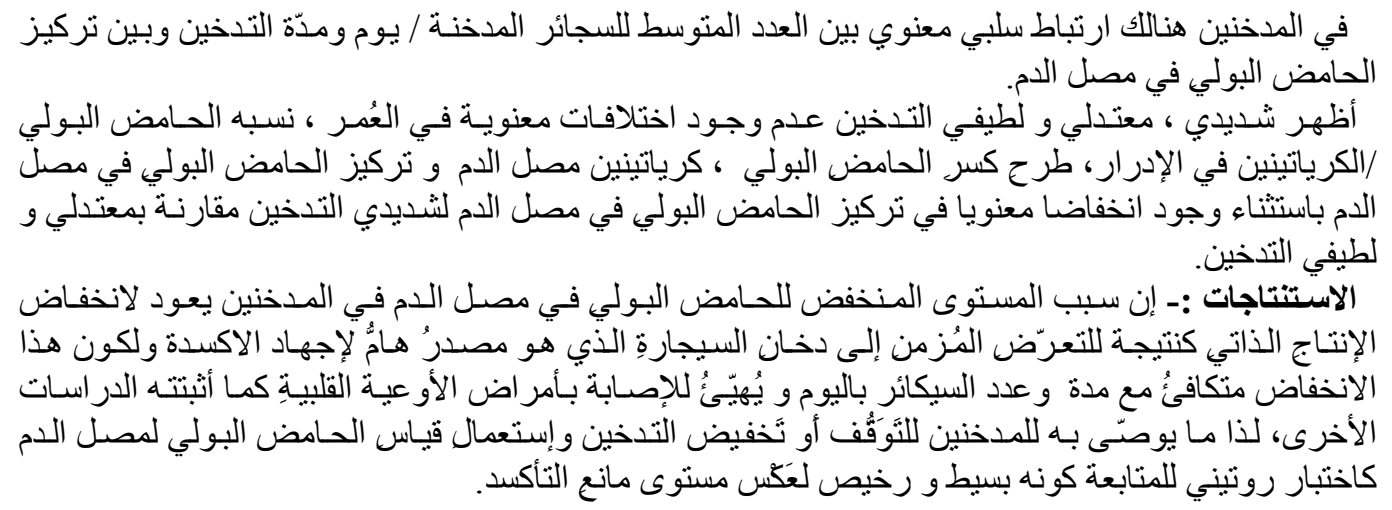

$C$ igarette smoking is a well-known risk

$\mathcal{G}$ factor for the development of atherosclerosis and its complications including cerebral and cardiovascular diseases(CVD)', through vascular endothelial damage. "This damage occurs possibly through the production of oxygen free radicals as superoxide radicals, hydrogen peroxide and hydroxyl radicals. Several enzymes can produce oxygen free radicals including xanthine oxidase, NADPH oxidase, myeloperoxidase, and endotoxin."

As cigarette smoke contains superoxide and reactive nitrogen species that readily react with various biomolecules, ${ }^{1,0,1}$ it has been hypothesized that some of the adverse effects of smoking may result from oxidative damage to endothelial cells, which results in nitric oxide shortage ${ }^{1, r, \lambda}$ that regulate vascular tone and accelerate insufficiency of coronary artery and vasoconstriction in many different tissues. ${ }^{r, 9}$ Therefore imbalance between oxidants and antioxidants may play an important role in the susceptible smoker.'",' In addition cigarette smokers also have increased inflammatory responses that further enhance their oxidative stress.",

Since in humans, uric acid(ur) is the most abundant aqueous antioxidant, accounting for up to $7 . \%$ of serum free radical scavenging capacity ${ }^{1 r}$ and is an important intracellular free radical scavenger during metabolic stress including smoking, ${ }^{1 r, 1:}$ therefore, measurement of serum ur reflect the antioxidant capacity."

The aim of this study is to demonstrate the possible effect of smoking on serum ur level.

\section{Patients and Methods}

The study was conducted during the period from March to June $r . . \wedge$ in Mosul city. Subjects enrolled in the study were divided into two groups (group' and group r).

Group 1 considered as control composed of $\leqslant \vee$ apparently healthy nonsmoker male volunteers, their ages ranged from $(r \cdot-\varepsilon \cdot)$ years.

Group $r$ is the smoker group composed of « - cigarette smoker male volunteers, their ages ranged from $r$. to $\varepsilon \cdot$ years . According to the number of cigarette smoked/day, this group is subdivided into heavy $(\geq \varepsilon \cdot$ cigarettes smoked/day, $n=q)$, moderate ( $r \cdot-r q$ cigarette smoked/day, $\mathrm{n}=1 \varepsilon)$ and mild ( $1-19$ cigarette smoked/day, $n=I v)$ smokers. ${ }^{10}$

A complete record of history was obtained, including name, age, average number of daily cigarette smoking, duration of smoking, dietary habit, pastmedical and drug history.

Neither group I nor group $r$ members had pastmedical history of diabetes mellitus, hyperuricemia and gout, renal, lung or heart diseases or drug history affecting ur and creatinine(cr) level or interfere with its measurement. Members of both groups had the same dietary habit.

Fasting blood samples for the measurement of serum ur and $\mathrm{cr}$ and random urine samples for the measurement of spot urine $\mathrm{cr}$ and ur were obtained from all subjects. The measurement of both serum and urine $\mathrm{cr}$ and ur were done by Jaffe's kinetic method using a kit supplied by biolabo company (France) and by uricase method" using a kit supplied by biomeriux company 
(France) respectively and are performed using Cecil spectrophotometer-CE 1.11 in the biochemistry laboratory at Nineveh College of Medicine in Mosul.

From the data of serum and urine ur and $\mathrm{cr}$, the calculation of both urine ur/urine $\mathrm{cr}$ (Uur/Ucr) ratio by dividing urine ur with urine $\mathrm{cr}^{\prime v}$ and fraction excretion of ur (FEur) by the formula [FEur = (Uur $\left.\left.\left.{ }^{*} \mathrm{Scr} / \mathrm{Sur}^{*} \mathrm{Ucr}\right)^{*}\right)^{\prime .}\right]^{1 /}$ were done in both groups.

The results were statistically evaluated by standard statistical methods including mean, standard deviation (SD), range (minimum-maximum), Linear regression analysis (Pearson correlation coefficient $r$ ) , student's t-test ${ }^{1 \wedge, 19}$ with computer software programs including Microsoft excel $r \ldots r$ and SPSS 11.0 to evaluate the relation between different parameters. Differences between observations were considered not significant at $P>\cdot . \cdot 0$.

\section{Results}

Table 1 demonstrates the mean \pm SD of the age, serum cr, serum ur, spot Uur/Ucr ratio and FEur in both groups. No significant differences in the age, serum cr, spot Uur/Ucr ratio and FEur between two groups $(P>\cdot .0)$. Serum ur was significantly lower in group $r$ compared with group ' $(P<\cdot . \cdot 1)$.

Table $r$ demonstrates the mean \pm SD and the range of the average number of cigarette smoked/day and the duration of smoking in group $r$.

Table $r$ demonstrates the subclassification of smoker group according to the number of cigarette smoked/day into heavy $(\geq \varepsilon$. cigarettes smoked/day), moderate ( $r \cdot-r q$ cigarette smoked/day) and mild (1-19 cigarette smoked/day) smokers with the mean \pm SD of their corresponding parameters including the age, serum $\mathrm{cr}$, serum ur, spot Uur/Ucr ratio and FEur . No significant differences in the age, Uur/Ucr ratio, FEur, serum $\mathrm{cr}$ and serum ur $(P>\cdot .0)$ except a significant lower serum ur value in the heavy compared with moderate $(P<\cdot . \cdot 1)$ and mild $(P<\cdot . \cdot 1)$ smokers .

Figure $\backslash$ and $r$; demonstrate a significant negative correlations $(P<\cdot \ldots 0)$ between serum ur and both the number of cigarette smoked/day and the duration of smoking respectively in group $r$.

Table 1: Comparison between parameters of group ${ }^{\prime}$ and $r$

\begin{tabular}{|c|c|c|c|}
\hline Parameter & $\begin{array}{c}\text { Group I } \\
\text { (Control) } \\
n=\Sigma v \\
\text { mean } \pm S D \\
\end{array}$ & $\begin{array}{c}\text { Group II } \\
\text { (Smokers) } \\
n=\varepsilon . \\
\text { mean } \pm \text { SD }\end{array}$ & P-Value \\
\hline Age (years) & $r \wedge . \varepsilon \pm 7$. & $r \cdot .0 \pm 7.1$ & NS \\
\hline Serum $\mathrm{cr}(\mu \mathrm{mol} / \mathrm{L})$ & $95.00 \pm 1 v .09$ & $\Lambda T . \varepsilon \cdot \pm Y V . Y \Lambda$ & NS \\
\hline Serum ur (mmol/L) & $\cdot r V_{ \pm} \cdot . \cdot 0$ & $\cdot r \varepsilon \pm \cdot \cdot \cdot V$ & $P<\cdot \cdot \cdot 1$ \\
\hline Uur/Ucr & $\cdot \varepsilon r \pm \cdot .11$ & $\cdot . \leq 7 \pm \cdot .11$ & NS \\
\hline FEur (\%) & $1 \cdot .1 \pm(.71$ & $11 . \wedge \tau \pm \tau . \wedge r$ & NS \\
\hline
\end{tabular}

NS : Not Significant 
Table $r$ : Number of cigarette/day and duration of smoking in group $r$

\begin{tabular}{|c|c|c|}
\hline Parameter & Mean \pm SD & Range \\
\hline Number of cigarette/day & r. ro \pm Ir.Tr & $0 . r$ \\
\hline Duration of smoking (Years) & $9, r \varepsilon \pm 0 . V r$ & $1.0-r$ r \\
\hline
\end{tabular}

Table r: Comparison between parameters (between each subgroup with the other two subgroups) of heavy, moderate and mild smokers

\begin{tabular}{|c|c|c|c|}
\hline Parameter & $\begin{array}{c}\text { Heavy Smokers } \\
n=9 \\
\text { mean } \pm \text { SD }\end{array}$ & $\begin{array}{c}\text { Moderate Smokers } \\
n=1 \leqslant \\
\text { mean } \pm S D\end{array}$ & $\begin{array}{c}\text { Mild Smokers } \\
n=1 \mathrm{~V} \\
\text { mean } \pm \text { SD }\end{array}$ \\
\hline Age (years) & $\begin{array}{c}\text { NS } \\
\text { NT. }\end{array}$ & $\begin{array}{c}\text { rq.r } \\
\text { NS }\end{array}$ & $\begin{array}{c}r 9.9 \pm 7.0 \\
N S\end{array}$ \\
\hline Serum $\mathrm{cr}(\mu \mathrm{mol} / \mathrm{L})$ & $\begin{array}{c}\wedge 9.9 \Lambda \pm r \cdot . \wedge 1 \\
N S\end{array}$ & $\begin{array}{c}9 \leqslant .0 r \pm r_{0 .} \cdot r \\
N S\end{array}$ & $\begin{array}{c}V Y . V Y \pm Y Y . r T \\
N S\end{array}$ \\
\hline Serum ur $(\mathrm{mmol} / \mathrm{L})$ & $\begin{array}{c}\because 11 \pm \cdot .0 \\
\downarrow \\
\downarrow\end{array}$ & $\begin{array}{c}\cdot r \leqslant \pm \cdot \cdot \cdot \cdot 0 \\
N S\end{array}$ & $\cdot r^{r V} \pm \cdot \cdot \cdot v$ \\
\hline Uur/Ucr & $\cdot \cdot r q \pm \cdot .11$ & $\begin{array}{c}\cdot \varepsilon r \pm \cdot r \cdot r \\
N S\end{array}$ & $\begin{array}{c}\cdot .0 \mathrm{Or} \pm \cdot .11 \\
\mathrm{NS}\end{array}$ \\
\hline FEur (\%) & $\begin{array}{c}1 r .0 r \pm r . \\
\text { NS }\end{array}$ & ${ }_{\mathrm{NS}}^{\mid r .0 \cdot \pm 1 \cdot .71}$ & $\begin{array}{c}1 . .0 Y \pm r . V q \\
N S\end{array}$ \\
\hline
\end{tabular}

Significant lower in heavy compared with moderate $(P<\cdot . \cdot)$ and mild $(P<\cdot, .1)$ smokers NS : Not Significant 


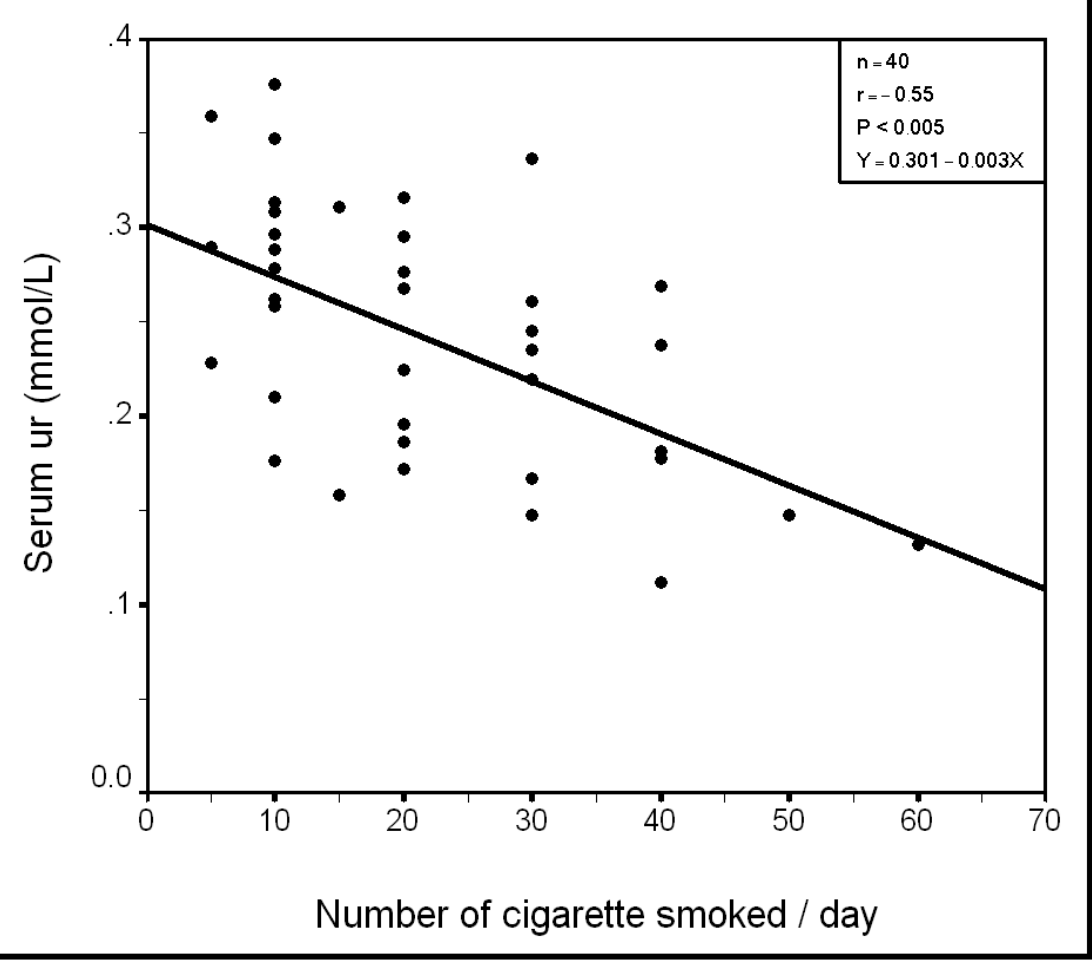

Figure 1: Correlation between serum ur and number of cigarette smoked/day in group II

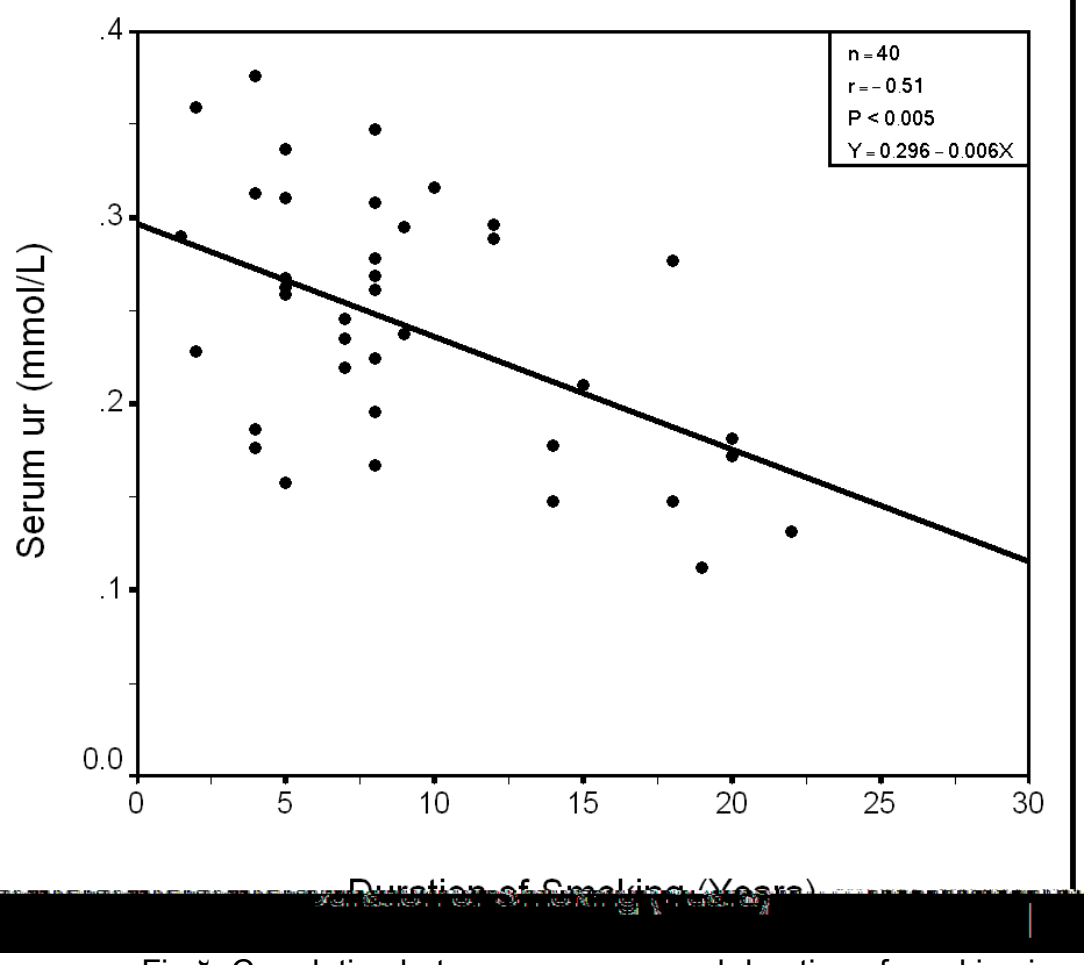

Fig r: Correlation between serum ur and duration of smoking in group II 


\section{Discussion}

Although many, but not all epidemiological studies have suggested that high serum ur is a risk factor for $C V D{ }^{r, r)}$ and independent predictor of death in patients at high risk for CVD. Many studies are warranted to evaluate its prognostic implications and potential utility in the monitoring of therapy. ${ }^{r}$ The raised level of serum ur parallel to an increased risk of CVD could be either primary or secondary to underling causes of CVD. ${ }^{r-T_{0}}$ However, the specific role of serum ur in this constellation remains uncertain ${ }^{r y}$ and the vital question is whether increased serum ur is a causal factor for CVD?. Observational data alone cannot answer that question.

In contrast, evidence suggesting that increase serum ur is protective against CVD since it acts as an endogenous antioxidant. ${ }^{r v, r \wedge}$ The higher serum ur levels found in CVD patients suggests that any protective antioxidant effect which ur has is overwhelmed by other negative effects on pathogenesis. ${ }^{r}$

The viability of administering ur in solution has been suggested ${ }^{r V}$ and so the role of ur as an independent cardiovascular risk factor has not been proved and the raising serum ur concentrations protects against oxidative damage in the setting of acute oxidative stress as in smoking."

After exclusion of factors affecting serum ur level, the significant reduction of serum ur is attributed to smoking and is negatively correlated to the duration and the number of cigarette smoked daily in spite of no significant difference between mild and moderate smokers which probably due to the vague history given by smokers on the number of cigarettes smoked/day, this finding is in agreement with other studies that found low serum ur in regular smoker, ${ }^{1, r}$ and reduction of antioxidants including ur in smokers. ${ }^{r Y, r T}$ Other study proved that after smoking, a similar reduction in the

concentration of plasma antioxidant compounds, such as cysteine, methionine and ur indicates that oxidative stress increases every time a cigarette is smoked.' Others proved that cigarette smokers and nonsmokers exposed to cigarette smoke have a significantly lower plasma antioxidant status than do unexposed nonsmokers, independent of differences in dietary antioxidant intakes. ${ }^{r}$ Other studies proved that excess free radical activity and endothelial dysfunction in smokers cause low baseline serum ur concentrations and that administration of ur raises circulating antioxidant defenses and allows restoration of endothelium-dependent vasodilatation. Therefore, high serum ur concentrations might be protective in situations characterized by increased cardiovascular risk and oxidative stress as in smoking ${ }^{\wedge}$ and by reduction of serum ur level in smokers it increase the susceptibility to oxidative damage and account for the excessive free radical production, ${ }^{r \varepsilon}$ therefore, the possibility that ur confers protection against the development of atherosclerosis, in view of its antioxidant properties, has been recognized. ${ }^{\text {ro }}$

In this study, serum cr, FEur and Uur/Ucr ratio are not significantly differ between two groups, in addition to that FEur and Uur/Ucr ratio values lie within the $\bar{X} \pm$ SD observed in the control group by other studies. ${ }^{Y, r y}$ Since these tests have been reported to be useful to evaluate renal handling of $u^{r v}$ and as serum ur concentrations are highly dependent on endogenous production ${ }^{\lambda}$ as well as renal excretion. $^{\text {ra }}$ Therefore, in this study it is concluded that the reduction of seum ur level in smokers is due to reduction of endogenous production rather than increase renal excretion. This reduction of endogenous production is due to both chronic exposure to cigarette smoke that is a significant source of oxidative stress which led to consumption of antioxidants including ur $^{0, r 5}$ which represent about $7 . \%$ of serum free radical scavenging capacity ${ }^{\prime \prime}$ and to the low intake of dietary antioxidants in smokers."

\section{Conclusion}

The significantly low serum ur level in smokers is due to the reduction of endogenous production as a result of chronic exposure to cigarette smoke that is a significant source of oxidative stress and as this reduction is proportionate with the duration and number of cigarette smoked/day, low ur is a predisposing factor to CVD as proved by other studies, therefore, it is recommended that for smokers to stop or reduce smoking with the use of serum ur as a routine test for follow-up as it is inexpensive and simple way to reflect antioxidant level. 


\section{References}

1. Tsuchiya M, Asada A, Kasahara E, Sato $\mathrm{EF}$, et al. Smoking a single cigarette rapidly reduces combined concentrations of nitrate and nitrite and concentrations of antioxidants in plasma. Circulation r...r:1.0:1100-110Y.

r. Celermajer DS, Sorensen K, Georgakopoulis D, Bull C, et al. Cigarette smoking is associated with dose-related and potentially reversible impairment of endothelium-dependent dilatation in healthy young adults. Circulation 199r; ^ᄉ: $r$ I $\leqslant 9-r 100$.

r. Benzuly KH, Padgett RC, Kaul S, Piegors DJ, et al. Functional improvement precedes structural regression of atherosclerosis. Circulation 199६; 19:111.-1111.

£. Kanani PM, Sinkey CA, Browning RL, Allaman $\mathrm{M}$, et al. Role of oxidant stress in endothelial dysfunction produced by experimental hyperhomocyst(e)inemia in humans. Circulation $1999 ; 1, \ldots 1171-1171$.

- Alberg A. The influence of cigarette smoking on circulating concentrations of antioxidant micronutrients . Toxicology r..r; $1 \Lambda \cdot(r): Y Y|-| r Y$.

7. Brown KM, Morrice PC, Duthie GG. Erythrocyte vitamin $\mathrm{E}$ and plasma ascorbate concentrations in relation to erythrocyte peroxidation in smokers and nonsmokers: dose response to vitamin $\mathrm{E}$ supplementation. Am J Clin Nutr 199\%; $70: \leqslant 97-0 . r$.

$\checkmark$. Node K, Kitakaze M, Yoshikawa H, Kosaka $\mathrm{H}$, et al. Reversible reduction in plasma concentration of nitric oxide induced by cigarette smoking in young adults. Am J Cardiol 199v; v9: 10rᄉ_10 1.

^. Waring SW, McKnight JA, Webb DJ, Maxwell SRJ. Uric acid restores endothelial function in patients with type 1 diabetes and regular smokers. Diabetes r... T; 00: rI YV_rITr.

१. Schectman G, Byrd JC, Gruchow HW. The influence of smoking on vitamin $C$ status in adults. $\mathrm{Am} \mathrm{J}$ Public Health 1919;:9:10人-17r.

1. Van der Vaart H, Postma DS, Timens W, Ten Hacken NHT. Acute effects of cigarette smoke on inflammation and oxidative stress: a review. Thorax $r . . \varepsilon$; $09 ; Y \backslash T-V Y)$.
11. Polidori MC, Mecocci P, Stahl W, Sies H. Cigarette smoking cessation increases plasma levels of several antioxidant micronutrients and improves resistance towards oxidative challenge $\mathrm{Br} J$ Nutr r..r; q. (1): $1 \leqslant v-10$.

Ir. Maxwell SR, Thomason H, Sandler D, LeGuen $C$, et al. Antioxidant status in patients with uncomplicated insulindependent and non-insulin-dependent diabetes mellitus. Eur J Clin Invest 199\%; $r V: \leq \wedge \leq-\varepsilon q$.

IT. Mathru M , Dries DJ, Barnes L, Tonino P, Sukhani R, Rooney MW. Tourniquetinduced xsanguinations in patients requiring lower limb surgery: an ischemia -reperfusion model of oxidant and antioxidant metabolism. Anesthesiology $1997 ; \wedge \leqslant: 1 \leqslant-r Y$.

I£. Hellsten Y, Tullson PC, Richter EA, Bangsbo J. Oxidation of urate in human skeletal muscle during exercise. Free

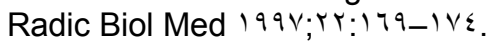

10. Ayanian JZ, Cleary PD. Perceived risks of heart disease and cancer among cigarette smokers. JAMA $1999 ; \nvdash \wedge 1: 1 \cdot 19_{-}$ 1.r. .

17. Whelton A, Watson JA, Robert RC. Nitrogen metabolism and renal function. In: Tietz fundamentals of clinical chemistry (Burtis CA, Ashwood ER, eds). sth ed. Saunders com 1997; OVA_- N. .

IV. Perez-Ruiz F, Calabozo M, GarcíaErauskin $G$, et al. Renal underexcretion of uric acid is present in patients with apparent high urinary uric acid output. Arthritis Rheum $r \ldots r$; $\leqslant v: r 1 \cdot-r) r$.

i^. Chap TLE. Introductory biostatistics. Wiely interscience r..r; rAr - rqr.

19. Jones D. Pharmaceutical statistics. Pharmaceutical press $r \ldots r$.

$r$. Fang J, Alderman MH. Serum uric acid and cardiovascular mortality the NHANES I epidemiologic follow-up study, 19V1-199r. National Health and Nutrition Examination Survey . JAMA r...;rAr:r $r \cdot\{\varepsilon-r \leqslant 1$.

$r$. Meisinger C, Koenig W, Baumert J, Döring A. Uric acid levels are associated with all-cause and cardiovascular disease mortality independent of systemic inflammation in men from the general population: the MONICA/KORA cohort study. Arterioscler Thromb Vasc Biol

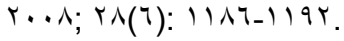


r. loachimescu AG, Brennan DM, Hoar BM, Hazen SL, et al. Serum uric acid is an independent predictor of all-cause mortality in patients at high risk of cardiovascular disease: a preventive cardiology information system (PreCIS) database cohort study. Arthritis Rheum. r..人;ON(T):TrT-Tr.

rr. Wheeler JG, Juzwishin KD, Eiriksdottir G , Gudnason V, et al. Serum uric acid and coronary heart disease in $9,\{0 \wedge$ incident cases and $100, \wedge \varepsilon$ controls: prospective study and meta-analysis. PLoS Med $r \cdot .0 ; r: e^{r \tau}$.

r๕. Ruggiero C, Cherubini A, Ble A, Bos AJ, et al. Uric acid and inflammatory markers. Eur Heart J $r . .7 ; r v: 11 v \varepsilon-11 \wedge$.

ro. Kawamoto R, Tomita H, Oka Y, Ohtsuka $\mathrm{N}$. Relationship between serum uric acid concentration, metabolic syndrome and carotid atherosclerosis . Intern Med Y.. $7: \leqslant 0: 7.0-7) \leqslant$.

זч. Dzielak DJ, Kivlighn SD. Emerging concepts in cardiovascular disease . Exp Opin Invest Drugs 1991 ; $\vee: \wedge 0_{-} \wedge 9$.

TV. Waring WS, Webb DJ, Maxwell SR . Systemic uric acid administration increases serum antioxidant capacity in healthy volunteers. J Cardiovasc Pharmacol $r \ldots l ;$ rA: rro_rVl.

r^. Schretlen DJ, Inscore $A B$, Jinnah $H A$, Rao V , Barry G, Pearlson GD. Serum Uric Acid and Cognitive Function in Community-Dwelling Older Adults . Neuropsychology $r \cdots v ; r)(1): \mid r \tau-1 \leqslant$.

rq. Torun M, Yardım S, Simsek B, Burgaz S. Serum uric acid levels in cardiovascular diseases . J clinical pharmacy and therapeutics $r \cdots \lambda ; r r: r 0_{-} r q$.

$r$. Waring WS, Convery A, Mishra V, Shenkin $A$, et al. Uric acid reduces exercise-induced oxidative stress in healthy adults. Clin Sci r..r; $1.0:$ \& ro$\varepsilon r$.

r. Timimi FK, Ting HH, Haley EA, Roddy $M A$, et al. Vitamin $C$ improves endothelium-dependent vasodilation in patients with insulindependent diabetes mellitus . J Am Coll Cardiol 199^; $r$ 1:00 r $00 \mathrm{~V}$.

rr. Dietrich M, Block G, Norkus EP, Hudes $M$, et al. Smoking and exposure to environmental tobacco smoke decrease some plasma antioxidants and increase gamma-tocopherol in vivo after adjustment for dietary antioxidant intakes . Am J Clin Nutr $r \ldots r ; Y V(1): 17 .-174$.

$r$ r. Goraca A, Skibska B. Plasma antioxidant status in healthy smoking and nonsmoking men. Bratisl L Listy r... ; $1 \cdot 7(1 \cdot): r \cdot 1-r \cdot 7$

$r \varepsilon$. Reilly $M$, Delanty $N$, Lawson JA, FitzGerald GA. Modulation of oxidant stress in vivo in chronic cigarette smokers. Circulation 1997;9 : 19 - ro.

ro. Nieto FJ, Iribarren C, Gross MD , Comstock GW, et al. Uric acid and serum antioxidant capacity: a reaction to atherosclerosis? Atherosclerosis r...; $1 \leqslant 1: 1 r 1-1$ rq.

rч. Katopodis KP , Elisaf MS , Pappas HA , Theodorou JCh, et al. Renal abnormalities in patients with sickle cellbeta thalassemia. J Nephrology 199V;1.(T):17r-1 TV.

rv. Perez-Ruiz F, Calabozo M, Herrero A, Ruiz-Lucea E, Alonso Ruiz A. Analysis of the methods for classifying gout according to renal excretion of uric acid . Rev Esp Reumatol 1991; ro:rro_rrq.

r^. Leyva F , Wingrove CS, Godsland IF, Stevenson JC. The glycolytic pathway to coronary heart disease: a hypothesis . Metabolism 199^; ₹V: 70V_Tr.

rq. Quinones GA, Natali A, Baldi S, Frascerra $S$, et al. Effect of insulin on uric acid excretion in humans. Am $\mathrm{J}$ Physiol 1990;rTM: El-0.

¿. Bloomer RJ. Decreased blood antioxidant capacity and increased lipid peroxidation in young cigarette smokers compared to nonsmokers: Impact of dietary intake.

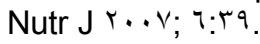

